\title{
ON SOME OF THE
}

\section{HISTOLOGICAL CHANGES}

\section{FOUND IN \\ CANCER OF THE SKIN OR EPITHELIOMA,}

\author{
WITH \\ SPECIAL REFERENCE TO THE SOURCE OF THE \\ NEWLY FORMED EPITHELIAL CELLS. \\ BY \\ GEORGE THIN, M.D.
}

(Received February 22nd-Read March 28th, 1876.)

THE opinions entertained by pathologists regarding the origin of the cells which form the epithelial growths that constitute one of the main features in cancer of the skin may be classified under the following heads :

Virchow and those who follow him believe that the epithelium which constitutes the new and morbid growth is formed by the cellular elements of the subjacent connective tissue.

Others, with Thiersch and Waldeyer, deny this participation of the subjacent connective tissue, and believe that the epithelial cells of the new growth are produced exclusively by proliferation of the pre-existing epithelial cells of the rete mucosum; glands, and hair-follicles.

Most of the best known names in pathology may be 
ranged on the side of one or other of these two views, although there is considerable difference of opinion regarding the manner in which the connective tissue on the one hand or the epithelium on the other is supposed to produce the new cells.

Exceptional views have been entertained by Köster, who believes that the new growth takes its origin in a proliferation of the epithelium of the lymphatic vessels, and by Classen, who in a case of cancer of the eyeball extending to the cornea convinced himself that the new cells were derived from the lymph-corpuscles.

The opinions which I shall develop in this memoir were formed after I had examined cancerous tumours from various parts of the body, and more especially after careful study of the appearances found in epitheliomata of the lip.

The preparations which are more particularly described, and from which the drawings have been made, were obtained from a case of epithelioma of the lip of a woman, diagnosed and operated on by Mr. Bell, of the Edinburgh Royal Infirmary.

I am indebted to Mr. Bell for the following notes of the case, which he has kindly sent to me at my request :

B. W-, æt. 67, from Penicuik, was the case from which I removed the specimen of epithelioma I sent to you for examination. She was a thin, somewhat withered old woman, who lived alone and supported herself by sewing. The malady was an exceedingly typical example of epithelioma, and had the usual history of the appearance, first of a small hard nodule, which broke, leaving an ulcer with a hard base, on which successive scabs formed and fell, leaving a steadily growing painful and fœtid ulcer. The pipe which she owned to using frequently was a very short and dirty black cutty. The glands were not affected. I removed it by a $\mathbf{V}$-shaped incision, and, as usual, with a rapid recovery. Such cases are exceedingly common in the male sex, and this was as perfect and typical a specimen as could be got. I am quite familiar 
with it in the female sex, having now operated seven times on old women, all of whom were in the constant habit of smoking dirty, short, hot pipes. I have never seen epithelioma in a female who did not smoke.

I enclose you a copy of the case as extracted from the hospital books.

\section{Extract from case-book.}

B. W-, æt. 67, a sewing woman, residing in Bread Street, Penicuik, was admitted into Ward 1, surgical, suffering from epithelioma of the lower lip, on January 28 th, 1875.

History.-About a year previous to admission the patient observed a small hard point in the lower lip close to the left angle of the mouth. About two months previous to admission the surface broke and an ulcer appeared, having a hard base and uneven edges. The patient stated that she had been accustomed to smoke, the pipe used being generally a short clay.

Appearance on admission.-A small ulcer existed at the situation above mentioned. It extended through the whole thickness of the lip, involving both skin and mucous membrane. The hardness did not extend far. The glands situated below the jaw and in the neck were not at all affected.

Treatment.-On the 30th January, 1875, Dr. Bell performed the following operation :

The epithelioma was removed by a $\mathbf{V}$-shaped incision; what arteries bled were not ligatured, but twisted. The edges of mucous membrane and skin were carefully brought together, the former by silk sutures and the latter by silver wire. During the evening after operation troublesome hæmorrhage supervened, and the house-surgeon, Dr. Cotton, was compelled to undo the stitches. The hæmorrhage was of the nature of a general oozing, which was in the end stopped by the use of Argentic. nitrate. Turpentine was administered internally in capsules. 
In the course of the afternoon of the 31 st Dr. Bell put in the stitches again. At this time the patient's pulse was 100 , and very weak.

February 1st.-Pulse stronger; reaction set in.

3rd.-As the edges of the wound showed a tendency to eversion, Dr. Bell put in a harelip needle.

9th.-Patient is getting on very nicely. The harelip needle was removed to-day.

11th.-Patient was to-day discharged.

Result.-Cured.

I found that the knowledge which can be obtained by examining sections of cancerous tumours depends very much on the mode of treatment to which the excised tumour is subjected. Profiting by this experience I treated the specimens which furnished the preparations, which I shall now describe, in the following manner :

Thin pieces were put in a one eighth per cent. solution of chromic acid, and the solution was changed daily for several days. They were then put in a quarter per cent. solution for two days, and finally in a half per cent. solution for four or five days.

The pieces thus hardened were embedded in wax and oil, and sections sufficiently thin for examination could be made. To obtain very thin sections subsequent hardening in methylated alcohol for twenty-four hours is advisable. But as a rule the less the specimen is brought into contact with alcohol the better. In sections cut directly after the action of the weak chromic acid, the abundant cell infiltration in the neighbourhood of the epithelial growth can be advantageously examined, the individual cells being well preserved.

If the sections are allowed to macerate for one or two days in distilled water they part with a portion of the chromic acid, and are then fitted for staining, solution of logwood acting readily on nuclei of cells so treated. The preparations should be examined in glycerine, as they suffer from the action of the alcohol and turpentine or oil 
of cloves which are necessary if Canada balsam or Dammar varnish is used.

I attach importance to these details because I have by following them obtained better preparations than when the tissues were hardened by stronger solutions of chromic acid and by alcohol.

Another series of preparations, and amongst them those to which I assign most importance, was obtained by the action of solution of osmic acid.

As the use of osmic acid in histological studies is in this country still comparatively limited, I may be pardoned a few preliminary remarks regarding the kind of effects which can be obtained by subjecting the fresh tissues to its action, as it will be necessary to bear these in mind in connection with the appearances I have to describe in the cancer preparations.

Osmic acid solution rapidly stains fat and medullated nerve-fibres black, but with its valuable uses in this respect $I$ have at present nothing further to do. It stains epithelial cells a varying shade of brownish yellow, fibrillary tissue is faintly coloured, and elastic fibres not at all. Lymph-cells acquire a faint dull hue, and are seen as granular bodies. The red blood-corpuscles are seen as rounded or quadrangular elements, in which the dark staining produced by the osmic acid is mingled with a slight tinge of their original colour. But distinct from the staining effects of the solution there is a peculiar "fixing" of all the tissue-elements.

Unlike many other hardening and staining reagents, it does not produce shrinking, and the most delicate structures are by its use preserved in their natural size and relations.

To understand the advantages which result from the application of osmic acid to the study of the histology of cancerous growths, it is only necessary to consider what has been already stated generally regarding its effects.

It stains the epithelium and the fibrillary tissue, fixes the free cells, makes the red blood-corpuscles prominent, vOL. LIX. 
enables us to identify colourless blood-corpuscles or lymphcells, and indicates gaps and spaces. It further hardens sufficiently to enable sections to be made without the use of alcohol.

I have not hitherto found that it stained the fixed cells of the connective tissue in cancerous skin, but as it has produced this result in other organs a similar effect in skin is probably only a question of successful manipulation. Immediately after Mr. Bell had excised the affected portion of the lip, thin slices through its whole thickness were placed in $\frac{1}{4}$ per cent. solution of osmic acid and sent me by post. I embedded portions of the slices the following day and prepared sections which were variously stained and mounted, sometimes in glycerine and sometimes in, what is better, a saturated solution of acetate of potash.

The results obtained by careful hardening in weak chromic acid were confirmed by the osmic acid sections, and appearances became visible which I had not detected by other methods.

The changes which the epithelial cells undergo in cancerous skin have been frequently described. I shall discuss separately the changes I observed in the cell and the nucleus. Like other observers I distinguish two kinds of change in the cell. In the centre of the enlarged rete mucosum and in the concentric layers of the laminated capsules the cells are scen to be much larger than in the normal tissue. 'They flatten out, sometimes become exceedingly long, twice or three times the length of an epidermic cell in healthy skin, and acquire a dried horny aspect. Others swell and have the appearance of a somewhat spherical, homogeneous, vitreous mass. One or more such cells may be often seen occupying the centre of a laminated capsule. I have satisfied myself that a laminated capsule frequently has its point of departure in an altered duct of one of the skin-glands, and I have found changes in the cells of little altered and recoguisable sweat-glands, which represent gradations between normal cells and the large vitreous cells in the centre of the laminated capsules. 
This is not, however, invariably the case. A cell of the rete mucosum sometimes undergoes the peculiar degeneration which indicates the first point of departure.

The cells of the sebaceous glands undergo changes in which the influence of their original peculiarities can be recognised, the waxy, somewhat glistening appearance of these cells being still distinctly visible. In a section which contains a great number of the cylindrical and pearshaped epidermic masses of cancerous skin it is often possible to distinguish the growths that have taken origin from the sweat- and sebaceous glands respectively by the peculiar appearances presented by the central cells. Growths, on the other hand, that spring from the interpapillary projections of the rete mucosum uniformly retain the usual characteristic aspect of the cells of that layer.

The cells that form the external layers of the deep projecting epithelial masses that can be recognised as enlarged sweat-glands and ducts have not the appearances which $I$ attribute to glandular origin, but on the contrary have nothing to distinguish them from the cells which are continuous with the rete.

The cells in the centre of the epithelial masses are, as a rule, larger thant hose on the borders, and in thin sections the serrate edges, which have given the designation "prickle cells" to epithelium on which they are seen, are more distinct than in normal epithelium. But they appear to be in no way connected with the cancerous development, which simply admits of their being more easily detected.

I can confirm Thiersch as against Köster, that the epithelial growth takes place from the rete mucosum, glands, and hair-follicles.

I have not once seen an epithelial cell constricted or marked by lines in any way whatever that would indicate that it was in process of dividing into two, or giving birth to an endogenous progeny, and after a careful examination of a great number of preparations $I$ have come to the conclusion that an epithelial cell in a cancerous tissue, although it undergoes various changes, never begets 
another cell-or cells. The idea of proliferation has originated, as I believe, in an erroneous interpretation given to certain changes that take place in the nucleus, which I shall now describe, and to other appearances seen in the débris of degenerated cells and nuclei, which I shall notice further on.

The nuclei of the epithelial cells in cancer may undergo a change similar to that which distinguishes the nuclei of the horny layer of the epidermis. They appear to dry and wither, and in the manipulation of the tissue they are apt to fall out of the cell, and instead of a nucleus a nuclear vacuole is left. In other cases the nucleus is suspended in the cell as an apparently dried, delicate, membranous substance, in the centre of which a large nucleolus is seen. The impression produced on the observer is as if the fluid contents of a vesicle had disappeared and had left behind an envelope and a network of exceedingly fine threads, in the centre of which the nucleolus is supported. The nucleus in this case is not larger than it is in the normal cell, but the nucleolus, if not actually larger, appears to be so, and I am disposed to believe that it is actually larger. At all events it is certainly altered in consistence and colour. It is darker than normal, and free nucleoli may be seen amongst the cells nearly as large as red blood-corpuscles, and having evidently a power of resistance which they do not possess in normal tissues. To judge by their resemblance in colour and appearance to the substance of the horny looking, enlarged, flattened cells, it would seem as if the change they had undergone was of a similar nature-that they had also undergone a horny degeneration.

Sometimes the withered nucleus can be seen to be divided by delicate radiating threads into four compartments, and in each compartment there is a small nucleolus. The aggregate bulk of the four nucleoli does not exceed that of the single enlarged nucleolus which I have just described. In this case the size of the entire nuclear space is neither enlarged nor constricted. The presence of 
several nucleoli in the nucleus may seem to justify the idea that the nucleus divides, but there is no evidence that there is any connection between the two processes. The more numerous the nucleoli are the smaller they are, from which I infer that they are a product of a division which is nothing more than a disintegration. I believe, for reasons into which $I$ need not enter further here, as the question is not an essential one in this connection, that the disintegration is a separation of elements which were originally isolated, and which were welded together when the cell assumed its permanent form.

A mode of division of the nucleus which is, as far as I have observed, rare, and the best-marked instances of which I have observed in preparations of scirrhus of the breast, is when, instead of one large nucleus, the cell contains several smaller rounded bodies, which are not bounded by a distinctly demarcated, vesicular, or nuclear space. Each of these bodies consists of a central point and a homogeneous border. They are smaller than any cellular element ever seen, either free, as forming part of the so-called cell-infiltration, or as forming one of the cells of the cancerous epithelium, and possess a characteristic appearance which, irrespective of size, would prevent their being confounded with anything else. I believe them to be products of disintegration of a nucleus which has swelled before going to pieces, and that the envelope which separates the nucleus from the other contents of the cell being ruptured, the nucleolar masses spread themselves through the substance of the cell. The appearance is, besides, sufficiently rare to be left out of account in a consideration of the question of cell growth.

In cancer the nucleus of the epithelial cell undergoes one of two transformations. It withers and falls into pieces, or in a swollen vitreous cell it undergoes the characteristic change that takes place in the cell-substance, but to a less degree apparently.

After the cell and nucleus have undergone further retrograde changes in addition to those which $I$ have de- 
scribed, another appearance is produced which is noteworthy, as being apt to lead to a mistaken idea regarding the growth of new cells. The original cell may have undergone molecular disintegration until there is nothing left of it but an uneven ring or ridge, which adheres to the adjacent tissue and corresponds to the contour of the cell. The rest of the cell and the nucleus have disappeared. I have seen this modified in so far as the cell was represented by two concentric ridges, an outer one corresponding to the contour of the cell, and an inner one to the circumference of the nucleus. Within these rings or ridges a lymph-corpuscle often fixes itself and, as we shall afterwards see, undergoes structural changes. It is then apt to be regarded as a product of the dead cell if the appearance is not carefully controlled by appropriate methods.

Thus, all the changes I have observed in the nucleus and cell are connected with death and disintegration. Of reproduction there is no evidence.

Surrounding the growing epithelial patches there is invariably to be observed a greater or less number of cells which are not seen in the normal tissue, and to these cells I now direct attention. They vary in size from that of the smallest lymph-corpuscles to that of an average red blood-corpuscle of the frog. Few of them attain the latter size. The smaller ones are rounded, but when seen in osmic acid preparations are frequently compressed laterally. The larger ones are mostly polygonal, a form evidently produced by the pressure they mutually exert on each other. The further we go from the epithelial growth the smaller the cells become, the very gradual transition stages by which the larger epithelial-looking cells pass into the small rounded corpuscles being almost imperceptible. In order to understand the disposition of these cells in the corium and subcutaneous tissue it is necessary to leave them for a little and consider the changes that take place in the fibrillary tissue in skin which is the seat of cancerous growth. And, first, one word in regard to 
the anatomy of that tissue. The fibrillary or gelatinous substance of the skin is composed of bands or bundles, and as the nomenclature which has been applied to the forms which these assume does not appear to me to be exact, it is necessary that I should define the terms I shall use. I recognise in the fibrillary tissue of the skin as a primary clement, a definite, even, somewhat flattened, cylindrical body of uniform calibre, the breadth approaching approximatively the diameter of a human red blood-corpuscle. When the cutis has been hardened in spirit all traces of the unity of structure of this band usually disappear, and portions of it split longitudinally are seen. 'The term white fibre has been applied indiscriminately to these longitudinal fractions of the bundle and to the bundle itself when seen entire. For this reason $I$ do not use the term in case it should lead to a misapprehension of my meaning. For a similar reason I reject the use of the word fibre as applied to this tissue. The term fibrilla is sometimes used in reference to these bundles and their fragments, being applied in the same way as the term white fibre. I reserve the use of the term fibrilla for a different element. It is possible by maceration in blood scrum or osmic acid, and with most certainty in the former, to resolve tendon into a multitude of exceedingly delicate threads or filaments. With more difficulty $I$ hare succeded in demonstrating the same extremely fine filaments in the fibrillary tissue of the skin, and to them I think the term fibrilla may be most appropriately applied. 'The next definite element is the cylindrical band already mentioned, and for convenience $I$ shall in this paper designate it a primary bundle. Several of these applied to each other longitudinally form the next definite structure, and I shall call it a secondary bundle. Large groups of such secondary bundles can often be distinguished in skin preparations, and may be designated tertiary bundles. Between these tertiary bundles ramify the larger blood-vessels and nerves. 
This nomenclature is not defended as the best that can be used, but it will serve until a better is selected, and the older terms are not sufficiently exact for my purpose.

In the skin of the dog Dr. Stirling (' Journal of Anatomy and Physiology,' 1876) has been able to isolate by artificial digestion sheaths which invest what he terms the "larger and very fine," what I should call the secondary and primary, bundles. In the human skin I have been able to fill the spaces between the tertiary bundles with metallic deposit, which indicated the presence in the spaces of a considerable quantity of lymph fluid. Without entering further into histological details I may state once for all that a constant circulation of lymph fluid between the primary bundles, between the secondary bundles, and between the tertiary bundles, may be fairly assumed. The lymph system of these spaces must not be confounded with the lymphatic vessels properly so called, and of which they are in the position of radicles. In the lymph fluid between the bundles a certain number of colourless blood-corpuscles (or lymph-corpuscles) are found normally. In inflammation and in other pathological conditions their number is greatly increased.

The fibrillary tissue in cancer of the skin is seen to be modified in two degrees. In the narrow papillæ compressed on both sides by the epithelial growth, and deeper in the corium when the growing epithelial masses approach each other, the arrangement in bundles is lost, and the tissue is represented by scant irregular shreds. It has to a great extent disappeared. These shreds of tissue often contain numbers of red blood-corpuscles in their meshes, and capillary vessels can often be detected amongst them in osmic acid preparations by the presence of the red bloodcorpuscles in unbroken lines.

Farther removed from the epithelial growth the arrangement in primary bundles is still intact, but the substance proper of the bundles has been to a great extent absorbed. The contour of the bundles is indicated by straight, 
unbroken, narrow lines of a highly refractive substance. Farther removed from the epithelial growth the condition of the bundles is normal.

The arrangement of the new cells to the fibrillary tissue will now be more easily understood. In the narrow clefts between the encroaching epithelium the shreds of the disorganized bundles are infiltrated with cells. As the relative arrangement of the cells is no longer determined by the fibrillary tissue, they are seen in sections either grouped in irregular masses or presenting the more or less regular appearance of a layer. In the adjacent parts, where the fibrillary tissue has been partly absorbed, but still retains its arrangement, the cells can be seen disposed in rows between the primary bundles or lying on them, their disposition being accurately in accordance with the anatomical relations of the bundles. When the accidental effect of the knife in cutting the section has been to isolate a secondary bundle more or less completely, it can be sometimes seen to be encrusted with the cells. The wide, frequently pyramidal-shaped, spaces between the tertiary bundles are often filled by masses of them.

But the cell infiltration does not stop here. In the surrounding fibrillary tissue, where the appearance and arrangement of the bundles are absolutely normal, single rows of cells can often be seen between the bundles, being a continuation of the same infiltration that is so abundantly present in the parts nearer the cancerous growth. The cell infiltration of cancerous skin extends, therefore, from the parts which are profoundly affected to the adjacent tissues, which are in other respects still apparently healthy.

The imperfect knowledge which we possess of the develop: ment and nature of the cellular elements of connective tissue renders an inquiry into the source of cell infil: tration, such as that present in cancer of the skin, a very difficult task. Their development from the epithelium of the rete or the glands, in spite of the most elaborate studies by many competent observers, remains in the present state of science a bare hypothesis, unsupported by 
any exidence stronger than the weight that is attributed to the division of the nuclens into several pieces. There has never been any satisfactory evidence adduced that this division of the nucleus is connected with a derelopment of new cells. In the cancerous process I have found that it is simply a stage in the cell disintegration, and in all the sections I have examined I have never seen any appearance that has indicated a development either by the proeess which is understood by the term proliferation or by endogenous eell growth. The appearances actually observed have been already described in detail, and $I$ believe they support $m e$ in denying that the source of the new cells is to be found in the pre-existing epithelium. In the present state of opinion regarding the histology of the skin the question seems to me to be limited to the consideration of one of two sources, and we have to decide whether these cells originate from cells already existing in the tissue or are derived by a process of extravasation from the blood-ressels. I presume that their origin from a blastema will hardly be considered a possible one.

I have now to consider whether the new growth may not spring by some process of what is called "proliferation" from the cells of the connective tissue. Here, however, we are at once met by the diffieulty that we know very little indeed about these cells. That a great number of cells exist is evident from the number of nuclei that can be stained by certain modes of preparation. Biesiadecki states that there are spindle (or fusiform) cells in the human corium, and this fact appears to me to have been demonstrated by $\mathrm{Dr}$. Stirling for the skin of the dog. Dr. Stirling's plates show further that there are large round nuclei in the skin, distinct from the spindle elements, but he leaves the nature of the cells to which these nuclei belong undetermined. As the result of researches which I have made on the cornea, to which I cannot do more than allude here, and of what is now established as regards tendon, I believe it is fair to assume that, in accordance with the similarity 
of structure, there must exist in the corium a system of flat cells applied to the surface of the bundles of fibrillary tissue. And, in point of fact, I have isolated from the cutis of the frog and the ox by warm saturated solution of caustic potash ${ }^{1}$ flat cells similar to those which by the same process I had isolated from the cornea. As far as I know, these cells have never been seen by any other process, but cells exactly similar have been isolated by Ranvier ${ }^{2}$ from the subcutaneous tissue into which a weak solution of nitrate of silver had been injected. The nuelei figured by Dr. Stirling seem to me to belong to the same cells, although it is right to mention that he regards them as belonging to lymph-corpuscles.

I have by means of several methods satisfied myself that there are stellate cells in the corium. The cell-protoplasm is very scant, and the fibres are straight and glistening, and do not stain in carmine or logwood. The plasmatic cell of Virchow is not a cell, but is simply a space between the bundles.

Thus, I believe that there exist in the skin stellate, spindle, and flat cells; but I hasten to remark that whether my views in this respect are for the present received or not, my general conclusions regarding the source of the cell infiltration remain unaffected, as my observations, which relate to the cells of the corium, are as regards this particular question entirely negative.

The existence of numerous stellate and spindle cells in the parts of the corium adjacent to the epithelial cancerous

1 For further details regarding this process see a memoir on hyaline cartilage in the 'Quart. Journ. Mic. Science,' January, 1876.

2 'Archives de Physiologie,' 1869. The exact bearing of Ranvier's discovery has been obscured by several subsequent investigators, who have deccribed isolated nuclei adherent to torn membranous substance as flat cells with fine processes. This error is due to unsuccessful manipulation. The flat cells of the subcutaneous tissue have no processes. They are easily demonstrated by injecting a weak solution of nitrate of silver under the skin of a mouse's back. It can then be seen further that they are not isolated, but that they form layers, such as that figured by me in the 'Proceedings of the Royal Society,' No. 155, 1874, figure 18, pl. ix. 
growth is indicated by minute fatty globules embedded in a granular substance which is seen in the spindle and in the stellate forms. These are prominent in osmic acid preparations, the fatty globules being stained black. This appearance is seen occasionally in cancerous skin, but I have met with it more frequently and much more abundantly in scirrhus mammæ. In the breast I have been able to follow the degenerating protoplasm into fine unstained processes, which demonstrated the nature of the cell. The distinction between the spindle cells and the cancerous epithelium was well marked.

No production of anything like new cells of any kind was ever found by me as taking place in these cells.

In thin sections of cancerous skin hardened in chromic acid or spirit and stained in logwood, minute stellate and spindle cells can be seen between the epithelium of the new growth. Little more than the nucleus is visible, but the beginning of the fine processes can generally be seen. The nucleus of the stellate cell is pyramidal and that of the spindle cell narrow and elongated. It is impossible to confound them with the epithelial cells, in whatever stage of growth or degeneration these may be. There is no transition between the minute, deeply stained nucleus of the branched cell and the large, round, faintly stained nucleus with central nucleolus of the epithelial cell. From the position and number of the nuclei and from what is visible of the processes it is evident that there is a highly developed interepithelial system of stellate and spindle cells in the epithelial growth of cancer. Similar nuclei and processes can be observed in the epithelium of healthy skin, although their demonstration is more difficult and succeeds to a less extent when the ordinary available methods are followed.

These preparations confirm the conclusion I have drawn from the osmic acid preparations-that the development of the epithelium is independent of the branched cells of the tissue.

In osmic acid preparations of cancerous skin large oval 
nuclei can be sometimes observed on thin membranous prolongations from the border of the rete, on the surface of isolated bundles, and in the walls of blood-vessels. These nuclei are faintly marked, show no signs of division, and nothing is seen of the cell to which they belong. They are distinct from any form of epithelial degeneration observed and from the lymph-cells. The nucleus is indeed larger than many of the latter. I have never observed these nuclei in osmic acid preparations of the healthy skin. I do not on this account connect their presence with cancer, but believe them to be the nuclei of the flat cells which are shown to exist in the skin by means of other processes. I have not observed them in preparations made from cancerous skin hardened by any other reagent than osmic acid. I infer that their appearance in epithelioma, whilst they are not seen in the healthy corium which has been subjected to the action of the same solution, is probably due to a change in the condition of the nucleus itself. At the same time it is not to be left out of account that the widening of the interstices of the tissue as a consequence of the morbid process may have resulted in the "fixing" of the nuclei by affording easy access to the entrance of the osmic acid.

It is important in considering the question of the possible development of cancerous cells from the flat cells of the corium to bear in mind that the nuclei which evidently belong to these cells are found unbroken and undivided, even when they are surrounded by cells of new formation. Amongst the drawings which accompany this paper is one (Fig. 2) which shows a secondary bundle with small cells clustering round it, and amongst these the oval nuclei on its surface are seen to be entire.

As far as it is possible to obtain evidence regarding the behaviour of cells of which we know so little as the cells of the corium, the presumption is strong that they have no share in the production of the new cells, and there is not a single fact known that suggests that they have anything to do with it. From the epithelial form and appearance 
which is characteristic of flat cells, it seemed to me at one time that the epithelial cells of the cancerous growth might possibly be due to some changed condition in these cells by which they attained the more advanced horny development of the epidermic cells. Of this, however, I have found no evidence, and the hypothesis is, in my opinion, excluded by the positive evidence that the cells are derived from another source, which I shall now indicate.

The cells which are found in rows between the apparently unaffected bundles of fibrillary tissue and the most of those between the bundles that are partly absorbed but still retain their form and arrangement are, in their microscopic appearances, indistinguishable from the lymph-corpuscles which are found in an inflamed cornea, and whose source it can be demonstrated is the extravasation from the conjunctival blood-vessels. I shall not recapitulate the observations and inferences on this subject which I have recently published at some length in a series of papers on inflammation in the 'Edinburgh Medical Journal,' but will state in a few words the kind of evidence which is obtainable on this point.

Solution of osmic acid fixes and stains colourless bloodcorpuscles within and without the blood-vessels in such a characteristic manner that they can be recognised with certainty. If an inflamed frog's tongue, in which extravasation has been observed under the microscope, is treated by osmic acid solution and examined, the arrangement of the colourless corpuscles in some of the sections can be recognised as similar to that which was observed in the transparent living tissue. The identity is beyond dispute. Estimated by this criterion, the cells which fill the spaces which are adjacent to the epithelial growth in a cancerous skin are extravasated colourless blood-corpuscles. When it happens that the section includes a blood-vessel, and a colourless corpuscle can be seen amongst the red corpuscles within the vessels, the absolute similarity between the colourless blood-cell within the vessel and the cells between the bundles is uumistakable. No stronger proof can be given 
unless the passage of the same cell could be followed from the vessel to the interstices of the tissue, which in the circumstances is manifestly impossible. To any one who will study the appearances of colourless blood-corpuscles when acted on by osmic acid this direct proof is as unnecessary as it is impossible. There is no other cell product with which I am familiar, certainly none connected with the phenomena of inflammation, which can be confounded with colourless blood-corpuscles in an osmic acid preparation.

Between the small rounded cells at the outskirts of the infiltration and the cells immediately adjoining the growing epithelium there is a difference in size and a difference as regards the more complete development of the nucleus. As regards both differences the transitions are very gradual. The nearer the epithelium, as a gencral rule, the larger the cell and the more completely developed the nucleus, but amongst the more developed cells are nearly always to be found some of the smaller cells which have undergone no change since they were extravasated from the vessels.

The development of a well-formed rounded nucleus is not dependent on the increased size of the cell, as in the small round cells amongst the bundles a greater proportion contain a round, single, fully formed nucleus than is the case with the lymph-cells in simply inflamed tissues. And here I would remark parenthetically that the hypothesis that the lymph-cells with multiple small nuclei are doomed to destruction is unproved. Observations of my own, which are still unpublished, lead me to believe that the multiple small nuclei which are found in many lymph-cells combine to form the single large nucleus which is found in other lymph-cells. According to this idea, the large number of lymph-corpuscles in cancerous infiltration which contain a single well-formed nucleus is due to a characteristic development of the cell after it has left the vessels.

The changes of which the lymph-corpuscles effused in a 
cancerous tissue are susceptible, and which many of them undergo, are an increase in the size of the cell and a development of the nucleus. That the latter is not dependent on the former is shown by the fact that an unusually large number of the corpuscles have a round complete nucleus before they have increased at all in size. In some instances, indeed, the nucleus constitutes nearly the whole of the cellular body.

The relation which these cells bear to the epithelium of the cancerous growth is an intimate one, and forms the foundation of the explanation I offer regarding that part of the morbid process which seems to me to constitute to a large extent its essential nature, namely, the continued extension of the epithelium by the formation of new epithelial cells.

The colourless blood-cells are in contact with the fully developed epithelium in three ways :

First, the contour of the epithelial growth may be sharply defined, an appearance indicating a delicate membrane forming a border or hem separating it from the contiguous elements. Adjacent to the epithelium one or two rows or layers of colourless cells are seen, which combine the appearance of epithelial with that of lymph-cells. They are continued indefinitely into the typical lymph-cells which fill the interstices of the tissue.

Secondly, the epithelial cells may be seen continued gradually into the lymph-cells, it being impossible to say where the one kind of cell ends and the other begins. The epithelial cells get smaller as they are nearer the edge of the growth, the outer parts of which are constituted by simple lymph-cells. In some preparations it is possible to observe small spindle cells among the lymphcells, and they can be traced into the fully developed epithelium.

Thirdly, in describing the changes that the epithelial cells of the cancerous growth undergo I mentioned that some of them degenerate until either the nucleus is repre- 
sented by a vacuole, or both nucleus and cell-substance may have disappeared, and nothing of the original cell is left but two concentric horny rings corresponding to the contours of the nucleus and the cell. Or all trace of the contour of the nucleus may have disappeared, and one such ring may be left corresponding to the contour of the cell. Into the vacant spaces thus left one or more lymphcorpuscles may enter, and fixing themselves in the position of the dead cell may develop into one or more epithelial cells which fill up the gap left by the withering of the previous occupant of the space.

The lymph-cells amongst the epithelium which are still unaltered can be identified by their size, the manner in which they are stained by carmine and logwood, and by the effect on them of osmic acid, in all of which respects they differ from the epithelial cells by which they are surrounded, and agree with the lymph-cells which are present in the spaces of the fibrillary tissue, and which are clustered round the extending epithelium.

Amongst the newly formed epithelial cells which have reached the full epithelial development transition cells from lymph-corpuscles to epithelium are not usually found deeper than in the two last-formed layers.

The thin membranous band which I have described as bounding the epithelial growth may be sometimes seen partially detached, and a connected mass of lymph-cells can be traced from the subepithelial tissue through the gap and into the fully developed epithelium.

Those lymph-corpuscles which are in the immediate neighbourhood of the epithelium partake to a certain extent of its characters, but when they are brought into direct contact with it they acquire all the characters of a fully developed epithelial cell.

The mode of development of the epithelial cells in cancerous tissue is intimately connected with that of the physiological regeneration of epithelium in healthy tissue and after destructive inflammatory processes. I have voL. LIX. 
made a series of investigations into the nature of the regenerative process in both these conditions.

In confirmation of what I have stated regarding the epithelial growth in cancer I cannot do more here than remark that the results of my researches, in so far as they have yet extended, accord with the opinions of those histologists who believe that the regeneration of epithelium takes place invariably by a special development of colourless blood-corpuscles.

The general conclusions at which I have arrived may be shortly expressed as follows :

In this disease there is an abnormal growth of epithelium and a morbid condition of the fibrillary tissue of the cutis. I do not know which of these factors is the earlier in point of time or the most important in point of development, but I am of opinion that the change in the fibrillary tissue is not due to pressure by the encroaching epithelium.

When the blood-vessels of a papilla are choked by the growing epithelium the destruction of the fibrillary tissue in the papilla is probably hastened, but in the cutis, long before any pressure can be exercised either on the vessels or tissue, the bundles have begun to undergo absorption. There is evidently a morbid influence in action here, which is totally distinct from the mere growth of the epithelial cells. Whether they both spring from a common cause or whether the one is the cause of the other is not apparent.

The extravasation of lymph-corpuscles into the spaces of the tissue is suggestive of the similar phenomenon in inflammation, and the mechanism by which it is called into action and effected is probably the same. It is quite conceivable that the abnormal epithelium may act as a foreigh body, and the effects of the injury it inflicts being propagated to the vessels, the weakened walls permit the extravasation. But there is an important difference in the cancerous as compared with the inflammatory change. Not only are the ordinary clinical symptoms of inflamma- 
tion absent, but its products do not follow. The material poured into the tissue from the blood does not organize. No newly formed connective tissue takes the place of the absorbed and degenerating bundles, a fact which has been already commented on by an author whose name I cannot at present recall. The plasma is either deficient in quality or its power to form the tissue is destroyed by some morbid agent developed in the part.

I am not inclined to attribute with the anthor to whom I have alluded this defective quality to a condition that affects the whole blood, because it is a matter of everyday experience that when a cancerous tumour is removed, in the wound so produced the healing process may be rapid and satisfactory. I am forced, therefore, to suppose that there is something in the cancerous part which is prejudicial to the formation of new tissue, and whatever that may be it is very probably to the same cause that the degeneration of the previously existing fibrillary tissue is to be attributed. This unknown agent may be a product of the abnormal epithelium, or both the abnormal epithelium and the degeneration of the connective tissue may, as I have already suggested, be due to a common cause.

The development of lymph-corpuscles into epithelium, when brought into contact with the epithelial cells already existing, being a process that, I believe, takes place also in healthy tissue, cannot be considered by me as in itself peculiar to cancer, but the abnormal extent to which the process develops is characteristic of the disease. This is shown, not only by the increased development which takes place in the immediate neighbourhood of the epithelium, but by changes in lymph-cells at a considerable distance from it, which are of a more or less marked epithelial character. The changed character of the large oval nuclei which I have described as being seen in the corium may be, perhaps, attributed to a similar influence.

We can only judge of the nature of this influence by its effects, and these we find to be analogous in one important feature to a change which is constantly taking place in 
physiological conditions. In health I believe that a lymphcorpuscle which is in contact with epithelial cells becomes assimilated to the cells with which it is in contact, and that this is the source of the regeneration of the epithelium, the area in which this change can take place being strictly limited. In cancer, on the other hand, the potential epithelial area extends along the lymph spaces of the adjacent tissue, and the lymph-cells that are present in it are subjected to a developmental change that they do not undergo in health except when in direct contact with normal epithelial structures. This influence, or epithelial infection as it has been termed, may exist both in the fluid and formed elements of the affected tissue, but that it is strongly present in the cells may be inferred from the rapid epithelial transformation which rows of cells undergo when they form an unbroken chain which is at one end in contact with the epithelial growth.

How much of the intensity of this influence is due to a more powerful action of the substance, whatever it may be, that produces epithelial growth, and how much to a diminished power of resistance on the part of the lymphcells, it is impossible to say, but both conditions are probably present.

The absorption of the fibrillary tissue which I have described as a change distinct from the growth of epithelium is probably produced by contact with a substance generated in the part, as it may be arrested for a period of years by a timely operation. This substance can only act on the tissues of the individual in whom it has been generated. The non-inoculability of cancer which may be inferred from the complete immunity from infection that is enjoyed by surgeons and nurses points to an abnormal condition of the tissue, which predisposes it to succumb to the morbid influence.

I have thus arrived at results similar to those obtained by Classen in the cancerous cornea, and as regards the growth of epithelium from colourless blood-cells in physiological conditions I am in accord with the views expressed 
thirty years ago by Addison and more recently by Biesiadecki and Pagenstecher.

As far as my investigations enable me to judge, the views I hold regarding cancer of the skin are applicable to cancer of other organs. With the exception of scirrhus mammæ these have, however, been limited, and in the case of cancerous breast I rest my opinion more on the instructive nature of osmic acid preparations than on the number of tumours examined.

Since the foregoing remarks were written a paper has appeared in 'Virchow's Archiv' (66 Band, 2e Heft) on the development of cancer in the diaphragm as a secondary growth, by Arcadius Rajewsky, and as the anthor states that his views regarding the nature of the process in the diaphragm are applicable to cancer of the skin, which he had also investigated, although details of the investigation are not given, it will not be out of place if $I$ add a few words regarding his memoir. His observations were made in Von Recklinghausen's laboratory, and it is to be presumed that the views expressed represent those of that pathologist.

$\mathrm{He}$ finds that cancerous epithelium extends from the. lymphatic vessels to the Saft Kanälchen, and that it is first formed by a proliferation of the lining epithelium of the vessel. The newly formed cells proliferate onwards and onwards in the lymph-channels. The substance of the bundles of tissue undergoes absorption. This observer is thus at one with myself regarding the relation which the newly formed cells have to the bundles, as the Saft Kanälchen are equivalent to the spaces which I have described as existing between them. He further confirms what I have stated in regard to the absorption of the tissue as an independent part of the cancerous process. He differs from me in believing that the growth of epithelium takes place first from the lymphatic vessels. My preparations teach me, on the contrary, that the new 
epithelium may form wherever there is an epithelial surface pre-existing.

I cannot find that the proliferation of the lymphatic epithelium is proved by Rajewsky. In the drawing (fig. 2 in his plate) I can only see a number of cells in an intermediate stage towards fully developed epithelium, and I see no evidence that a cell is dividing into two or more cells, or that any one of the cells figured has been produced by any one of the others. The resemblance of the smaller cells between the bundles to lymph- or colourless bloodcorpuscles had not escaped him. He remarks that the cells which are more distant from the cancer-centres might be taken for "wandering cells," that is, lymphcells. He adds that such an admission as to their nature can hardly be made (although he does not explain why), and considers it more probable that they are products of such proliferation as is supposed to be represented in the drawing to which I have referred, and which I cannot see represents any such process as is indicated by that term.

I fail to see that this latest author has added anything that makes the proliferation theory less of an hypothesis and more of a fact than it has always been, while it is satisfactory to be able to claim such an authority as that of Von Recklinghausen in testimony of the impossibility of distinguishing between colourless blood-corpuscles and the first appearance of the cells that will afterwards become unmistakable cancer-epithelium.

In conclusion I have to express my thanks to $\mathrm{Mr}$. Bell, of the Edinburgh Royal Infirmary, for the kind manner in which he has provided me with material for this investigation, and to Mr. Ewart for executing the accompanying drawings. 


\section{DESCRIPTION OF PLATE $\mathrm{X}$.}

All the figures are drawn from osmic acid preparations. The magnifying power is that of the No. 7 objective of Hartnack, with No. 3 eyepiece, which is equal to about 300 diameters.

Fic. 1.-The substance of the bundles of the fibrillary tissue has been absorbed, but the boundaries of the bundles $(a)$ persist. The arrangement of lymph-cells $(b)$ is still determined by that of the bundles.

Fra. 2.-A secondary bundle on which the nuclei of flat cells of the normal tissue $(b)$ still persist. Lymph-cells $(a)$ still retaining their characteristic appearance are seen on the surface of the bundle.

FrG. 3.-Primary bundles (b) which still present the normal appearance. Lymph-cells (a) between the bundles. Nuclei of the normal tissue $(c)$ seen on the bundles.

Fra. 4.- Part of a section in the vicinity of abundant cell infiltration. (a) Cells of the rete Malpighii; (b) transparent membranous tissue adherent to the rete; (c) large oval nuclei of the normal tissue persisting; $(d)$ a blood-vessel ; $(e)$ lymph-corpuscle (colourless bloodcorpuscle) within the vessel.

FIG. 5.-Growth of new epithelium by apposition of lymphcorpuscles, between which minute spindle elements extend into the rete. (a) Cells of epidermis (prickle cells) in the horny condition; (b) cells of rete Malpighi presenting a normal appearance; (c) lymphcorpuscles; $(d)$ spindle-cells.

FIG. 6.-Section of rete and subjacent tissue, torn in order to facilitate the examination of the individual cells. (a) Cells of rete Malpighii; (b) lymph-corpuscles in transition to epithelium; (c) lymph-corpuscles showing first stage of the epithelial change; (d) fibrillary tissue; (e) lymph-corpuscle unaltered.

FiG. 7.-Cells which have undergone horny degeneration. (a) Transparent homogeneous substance within a horny ring; (b) horny ring from which the cell-substance has fallen out.

FIG. 8.-Shows an early stage in the formation of a laminated capsule. (a) A swollen vitreous cell; (b) indicates a capsule of withered horny epithelium.

FIG. 9.-A cell in a sebaceous gland undergoing horny degeneration. (a) Horny ring round the nucleus, which is represented by granular débris; (b) edge of withered cell-substance which is separated from the nuclear horny ring; (c) horny ring surrounding the cell. 


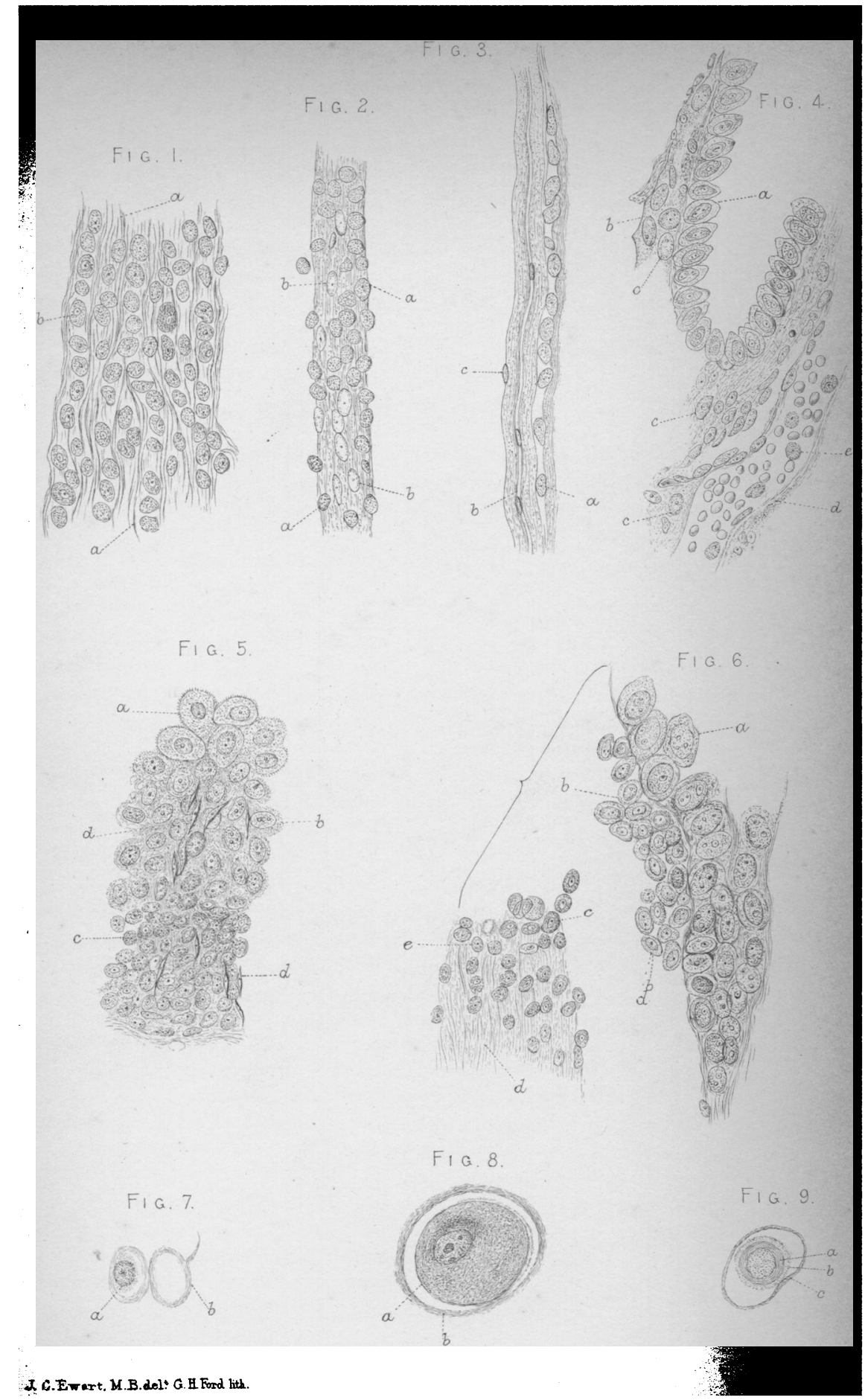

